\title{
Overview of implantable cardioverter defibrillator and cardiac resynchronisation therapy in heart failure management
}

Pow-Li $\underline{\text { Chia }}^{1}$, MBBS, MRCP, David $\underline{\text { FoO }}^{1}$, MBBS, MRCP

\begin{abstract}
Clinical trials have established the benefits of implantable cardioverter defibrillators (ICDs) and cardiac resynchronisation therapy (CRT) in the treatment of heart failure patients. As adjuncts to guideline-directed medical therapy, ICDs confer mortality benefits from sudden cardiac arrest, while CRT reduces mortality, hospitalisation rates and improves functional capacity. This review discusses the use of ICDs and CRT devices in heart failure management, outlining the evidence supporting their use, indications and contraindications.
\end{abstract}

Keywords: cardiac implantable electronic devices, cardiac resynchronisation therapy, heart failure, implantable cardioverter defibrillator

\section{INTRODUCTION}

In Singapore, the age-standardised incidence rate of acute myocardial infarction increased from 208.9 per 100,000 in 2007 to 221.2 per 100,000 in 2013. During the same period, the age-standardised mortality rate from acute myocardial infarction decreased from 40.8 per 100,000 to 26.0 per 100,000, with heart failure being one of the top complications. Consequently, the overall heart failure disease burden in Singapore has increased over the years to make heart failure one of the most common cardiac causes of hospital admission. ${ }^{(1)}$

In addition to guideline-directed medical therapy (GDMT), implantable cardioverter defibrillators (ICDs) and cardiac resynchronisation therapy (CRT) have been reported to be effective adjuncts in heart failure management. These devices have been shown to be useful for the prevention of sudden cardiac death (SCD) and progressive pump failure, the two main causes of cardiac death in patients with left ventricular (LV) dysfunction. This review discusses ICDs and CRT devices and the roles they play in heart failure treatment.

\section{Implantable cardioverter defibrillator}

Patients with LV dysfunction are at an increased risk of SCD secondary to ventricular tachyarrhythmias. The risk of SCD increases with decreasing LV ejection fraction. ${ }^{(2-6)}$ Those who have experienced previous sustained ventricular tachyarrhythmias or unexplained syncope are at the greatest risk of SCD. The ICD is a device capable of detecting and terminating ventricular tachyarrhythmias. It consists of leads attached to a pulse generator that houses the batteries, microprocessors and capacitors. An ICD pulse generator is usually implanted subcutaneously in the left anterior chest wall under local anaesthesia and conscious sedation, with leads introduced into the cardiac chambers via the subclavian or cephalic vein. A single-chamber ICD has a single defibrillator lead implanted in the right ventricle (Fig. 1), while a dual-chamber ICD has a right atrial pacing lead and a right ventricular defibrillator lead. A biventricular ICD, also known as a CRT-defibrillator, has a right ventricular defibrillator lead and a left ventricular pacing lead placed via the coronary sinus (Fig. 2). Depending on whether the patient has permanent atrial fibrillation, an atrial pacing lead may be used. When an ICD detects ventricular tachyarrhythmias based on physicianprogrammed algorithms, it initiates therapy by way of antitachycardia pacing and/or defibrillation shocks. In addition to anti-tachycardia therapy, ICDs are also capable of backup bradycardia pacing and heart rhythm monitoring with electrogram storage.

In large prospective trials for the secondary prevention of SCD, such as the Antiarrhythmics Versus Implantable Defibrillators study, Cardiac Arrest Study Hamburg and Canadian Implantable Defibrillator Study, ICD use resulted in relative risk reduction of up to $50 \%$ for arrhythmic deaths and $25 \%$ for allcause mortality. ${ }^{(7-12)}$ Studies evaluating the secondary prevention of SCD have consistently shown better survival with ICD therapy compared to anti-arrhythmic medications. ${ }^{(12)}$

The Sudden Cardiac Death in Heart Failure Trial (SCD$\mathrm{HeFT}$ ) and Multicenter Automatic Defibrillator Implantation Trial II (MADIT-II) provided evidence supporting ICD use for the primary prevention of SCD in patients with LV dysfunction. Importantly, all patients who were studied had already been on at least 3-6 months of GDMT. In SCD-HeFT, patients had LV ejection fraction $\leq 35 \%$ with New York Heart Association (NYHA) Class II or III symptoms secondary to ischaemic or non-ischaemic causes. There was a $23 \%$ relative reduction in risk of death and $7 \%$ absolute reduction in mortality after five years of ICD use. ${ }^{(13)}$ Patients who were randomised to the ICD arm had $60 \%$ reduction in SCD. ${ }^{(14)}$ The reduction in all-cause mortality was independent of ischaemic or non-ischaemic aetiologies of cardiac failure. In MADIT-II, patients had LV ejection fraction $\leq 30 \%$ and were at

${ }^{1}$ Department of Cardiology, Tan Tock Seng Hospital, Singapore

Correspondence: Dr Chia Pow-Li, Consultant, Department of Cardiology, Tan Tock Seng Hospital, 11 Jalan Tan Tock Seng, Singapore 308433. powlichia@gmail.com 


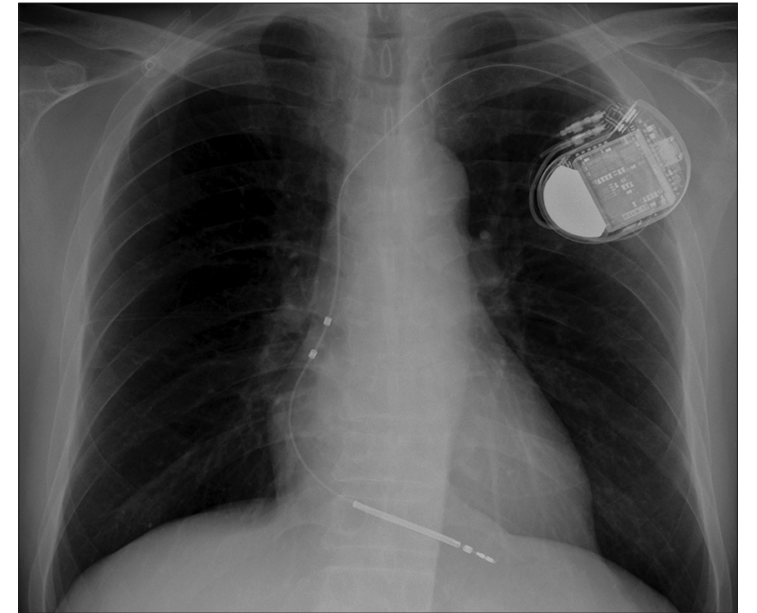

Fig. 1 Radiograph shows a single-chamber implantable cardioverte defibrillator with a thick radiopaque shocking coil in the right ventricular defibrillator lead.

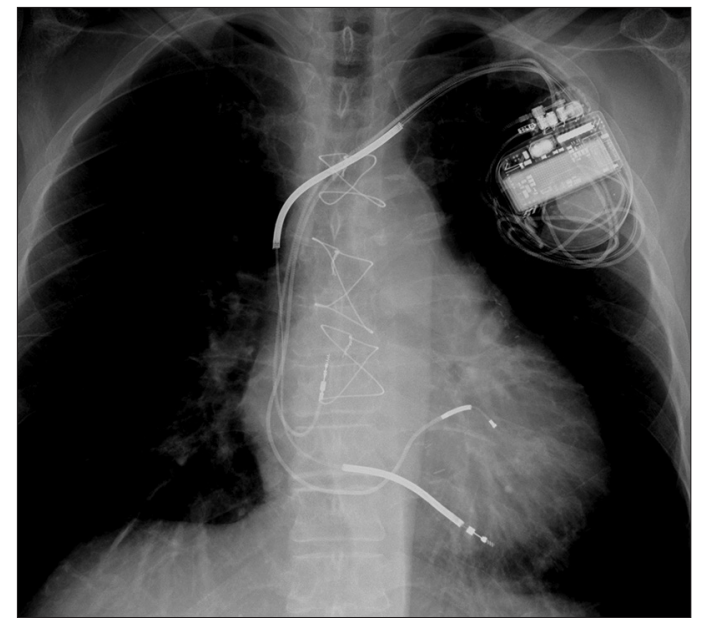

Fig. 2 Radiograph shows a biventricular defibrillator or cardiac resynchronisation therapy-defibrillator with a right atrial lead and right ventricular defibrillator lead, as identified by the presence of shocking coils and a left ventricular lead coursing through the coronary sinus to pace the left ventricle.

least 30 days post-myocardial infarction. All-cause mortality was reduced by $31 \%$ with ICD use; patients whose index heart attack was more distant from the point of randomisation derived more benefit from ICD therapy. ${ }^{(15,16)}$

For patients with LV dysfunction secondary to non-ischaemic aetiologies, the DEFibrillators in Non-Ischemic Cardiomyopathy Treatment Evaluation (DEFINITE) and SCD-HeFT trials supported the use of ICD for the primary prevention of SCD. The DEFINITE trial also used an LV ejection fraction cut-off criterion of $\leq 35 \%$. Both trials showed decreases in all-cause and arrhythmic mortality. ${ }^{(13,17)}$ Desai et al performed a meta-analysis of five primary prevention trials involving 1,854 patients with nonischaemic heart failure and reported a significant $31 \%$ reduction in total mortality with ICD use. ${ }^{(18)}$

Current evidence does not support ICD therapy in patients with NYHA Class IV end-stage cardiac failure or an estimated life expectancy of less than one year. ICDs are also not recommended for the primary prevention of SCD in NYHA Class I patients and cases of heart failure with preserved LV ejection fraction. ${ }^{(19)}$
Older patients are underrepresented in ICD trials, where the average patient age is 65 years or less. ${ }^{(20)}$ Trials for the secondary prevention of SCD revealed no benefit in patients aged 75 years or older and a meta-analysis of trials for the primary prevention of SCD suggested that ICD therapy was less efficacious in older patients. ${ }^{(21,22)}$ Patients with repeat hospitalisation for heart failure, especially when coupled with chronic kidney disease, may also benefit less from ICD therapy. ${ }^{(23)}$

With the exception of MADIT-II, most other trials evaluating ICD efficacy involved only single-chamber devices or very few dual-chamber ones. ${ }^{(24)}$ Studies evaluating the clinical superiority of dual- versus single-chamber ICDs have shown mixed results. Some reports suggested that the dual-chamber ICD provided clinical benefits in arrhythmia differentiation, prevention of inappropriate ICD therapy and patients who required pacing for bradyarrhythmias. ${ }^{(25-29)}$ However, Dewland et al pointed out that complications were more frequent during the implantation of dual- versus single-chamber ICDs $(3.17 \%$ vs. $2.11 \%$; $p<0.001)$, with a higher in-hospital mortality $(0.40 \%$ vs. $0.23 \%$; $p<0.001) .{ }^{(24)}$

Taking into account existing best evidence, American and European guidelines ${ }^{(19,30)}$ recommend the following criteria as Class I indications for ICD implantation in patients with LV dysfunction:

1. Documented ventricular fibrillation or haemodynamically unstable sustained ventricular tachycardia with no identifiable reversible causes; on GDMT; and with good functional capacity and life expectancy of more than one year.

2. Ischaemic or non-ischaemic LV dysfunction with ejection fraction of $\leq 35 \%$; and NYHA Class II or III status, with good functional capacity or life expectancy of more than one year (for patients with ischaemic LV dysfunction, the index acute myocardial infarction should be 40 days or longer). European guidelines further recommend that patients should be on at least three months of GDMT.

3. Ischaemic LV dysfunction and ejection fraction of $\leq 30 \%$; NYHA Class I status; and at least 40 days post-myocardial infarction with good functional capacity and life expectancy of more than one year.

Conversely, ICD implantation is contraindicated in the following clinical situations:

1. Estimated life expectancy of less than one year and/or poor functional capacity.

2. Incessant ventricular tachyarrhythmias.

3. NYHA Class IV patients who fail to respond to GDMT and are not deemed suitable for cardiac transplantation or CRT.

4. Ventricular tachyarrhythmias that are amenable to surgical/ catheter ablation or secondary to reversible causes.

\section{Cardiac resynchronisation therapy}

As heart failure progresses, electrical remodelling occurs and the QRS duration may be considerably prolonged in up to one-third of patients, resulting in a poorer outcome. ${ }^{(31)}$ Intraventricular and interventricular mechanical dyssynchrony develop as a result of electrical remodelling and, in turn, negatively impact cardiac contractile performance. CRT or biventricular pacing confers 
benefits on such patients through improvements in ventricular contractility, functional mitral regurgitation, ventricular remodelling and overall LV ejection fraction. As it results in increased blood pressure, doses of GDMT may be further optimised with the potential for greater improvement.

Two randomised controlled trials (the Comparison of Medical Therapy, Pacing and Defibrillation in Heart Failure [COMPANION] trial and the CArdiac Resynchronisation-Heart Failure [CARE-HF] trial) have shown that in patients with reduced LV ejection fraction, sinus rhythm, NYHA Class III and ambulatory Class IV symptoms, CRT decreases morbidity and mortality. ${ }^{(32,33)}$ Both trials enrolled patients with QRS duration > 120 ms. Allcause mortality was reduced by up to $36 \%$. In the COMPANION trial, CRT-defibrillator use, but not CRT-pacemaker, decreased SCD rate, while in the extended CARE-HF trial, which had a mean follow-up duration of 37 months, CRT-pacemaker use also decreased SCD by $46 \%$. Both trials provided compelling evidence supporting the use of CRT in heart failure patients who have reduced LV ejection fraction; NYHA Class III or ambulatory Class IV symptoms; QRS duration > 120 ms; and, in particular, those with left bundle branch block (LBBB) morphology. Other trials, registries and meta-analyses subsequently reported findings corroborating those of the COMPANION and CARE-HF trials. ${ }^{(34-36}$ In a meta-analysis by Sipahi et al, CRT use was associated with a significant reduction in all-cause mortality or hospitalisation rates in patients with QRS duration > $150 \mathrm{~ms}$, but not in those with a QRS duration of 120-150 ms. ${ }^{(37)}$

In patients with mild heart failure, two randomised controlled trials have shown the benefits of CRT over optimal GDMT. The Multicenter Automatic Defibrillator Implantation Trial with Cardiac Resynchronization Therapy (MADIT-CRT) evaluated patients with LV ejection fraction $<30 \%$, NYHA Class I or II symptoms, and QRS duration > $130 \mathrm{~ms}$. It reported a 34\% reduction in all-cause mortality or heart failure events with the use of CRT. After seven years of follow-up, patients with ICDs were compared to those with CRT-defibrillators and a significant reduction in mortality was found in patients with baseline LBBB. ${ }^{(38)}$ The Resynchronisation-Defibrillation for Ambulatory Heart Failure Trial, which enrolled patients with LV ejection fraction $<30 \%$, QRS duration $>120$ ms or NYHA Class II or III symptoms, reported a significant $25 \%$ relative reduction in allcause mortality when comparing patients with CRT-defibrillator and those with ICD. ${ }^{(39)}$

The Dual Chamber and VVI Implantable Defibrillator (DAVID) trial ${ }^{(40)}$ and Mode Selection Trial ${ }^{(41)}$ showed that right ventricular pacing was associated with an increased hospitalisation rate for heart failure, suggesting that CRT confers clinical benefits in patients with reduced LV function and a need for pacing. ${ }^{(42)}$ In the DAVID trial, patients with a right ventricular pacing burden of $>40 \%$ had poorer outcomes. The Biventricular versus Right Ventricular Pacing in Heart Failure Patients with Atrioventricular Block trial corroborated these findings with revelations that CRT was associated with a $26 \%$ decrease in primary composite endpoint (total mortality, urgent heart failure care or an increase in LV end-systolic volume) when compared with right ventricular pacing in cardiac failure patients with conventional indications for pacing. ${ }^{(43)}$

Patients with permanent atrial fibrillation derive appreciably fewer clinical benefits from CRT. ${ }^{(44,45)}$ However, long-term survival following CRT in atrial fibrillation patients who have undergone atrioventricular (AV) node ablation is similar to that of patients with sinus rhythm. AV node ablation ensures a high degree of biventricular pacing, which is essential for effective CRT. ${ }^{(46)}$

Elderly patients were underrepresented in the main randomised CRT clinical trials, whose participants had a mean age of $64-68$ years. ${ }^{(31-33)}$ However, there is published data suggesting that CRT is safe and effective for the elderly. A subgroup analysis of MADIT-CRT evaluating the degree of LV end-systolic volume change at 12 months follow-up among patients aged $<60$ years, $60-74$ years and $\geq 75$ years found no significant differences between age groups. ${ }^{(47)}$ Comparable findings were also reported in subgroup analyses involving patients from COMPANION, ${ }^{(32)}$ CARE-HF ${ }^{(33)}$ and several cohort studies. ${ }^{(48-50)}$ Device-related complication rates did not differ across age groups. In a COMPANION subgroup analysis, there was no significant difference in survival rates between elderly and non-elderly patients. ${ }^{(32)}$

Current established Class I indications for $\mathrm{CRT}^{(51,52)}$ include patients who fulfil the following criteria:

1. NYHA Class III or ambulatory Class IV symptoms; LV ejection fraction $\leq 35 \%$; baseline LBBB; sinus rhythm; and QRS duration of $\geq 150 \mathrm{~ms}$ on optimal GDMT (European guidelines recommend at least three months of GDMT).

2. NYHA Class I or II symptoms; LV ejection fraction $\leq 30 \%$; baseline LBBB; sinus rhythm; and QRS duration $\geq 130 \mathrm{~ms}$ on optimal GDMT (European guidelines recommend at least three months of GDMT).

3. Upgrade from a cardiac permanent pacemaker or ICD in a patient with LVEF $\leq 35 \%$; high percentage of ventricular pacing; and NYHA Class III or ambulatory NYHA Class IV symptoms.

At this juncture, there is no evidence to support the use of CRT in patients with non-LBBB electrocardiography patterns, QRS duration < 120 ms or survival of less than one year. The Evaluation of Resynchronization Therapy for Heart Failure and Echocardiography Guided Cardiac Resynchronization Therapy (EchoCRT) trials provided evidence that in patients with mechanical dyssynchrony but narrow QRS duration (<130 ms), CRT did not improve clinical outcomes or reverse LV remodelling, and instead increased mortality. ${ }^{(53,54)}$

Despite fulfilling the selection criteria, up to one-third of patients may not exhibit a response to CRT. ${ }^{(55)}$ To date, there is no standard definition of CRT response. Some studies reported CRT response in terms of clinical parameters such as the heart failure clinical composite score, which combines all-cause mortality, heart failure hospitalisation rate, NYHA class and patient global assessment into an outcome measure. ${ }^{(31,56)}$ Others evaluated response in terms of echocardiographic parameters such as $\geq 15 \%$ reduction in left ventricular end-systolic volume. ${ }^{(57,58)}$ Published data revealed a discrepancy between clinical and 
echocardiographic responses, with more studies reporting clinical response than echocardiographic improvement. ${ }^{(59)}$

Reduced response to CRT has been associated with a high myocardial scar burden, ${ }^{(60)}$ posterolateral ${ }^{(61)}$ and mid-wall ${ }^{(62)}$ scar location, extreme mechanical dyssynchrony, ${ }^{(63)}$ severe right ventricular dysfunction, pulmonary hypertension, end-stage renal failure, and valvular heart disease. On the other hand, better CRT outcomes have been reported in female patients ${ }^{(64,65)}$ and those with non-ischaemic cardiomyopathy. ${ }^{(62)}$

Efforts have been made to identify factors which may better predict response to CRT. The Predictors of Response to CRT trial ${ }^{(66)}$ and EchoCRT study ${ }^{(54)}$ revealed that echocardiographic measures of mechanical dyssynchrony did not reliably predict CRT response. Consequently, clinical guidelines on CRT do not recommend use of echocardiographic parameters for patient selection. The role of imaging in patient selection for CRT has shifted toward identification of optimal LV pacing sites. The Targeted Left Ventricular Lead Placement to Guide Cardiac Resynchronization Therapy study ${ }^{(67)}$ and Speckle Tracking Assisted Resynchronization Therapy for Electrode Region trial(68) reported that CRT outcomes may be improved by using echocardiography to identify late-activated segments for LV pacing. The use of cardiac magnetic resonance imaging to assess myocardial scar burden and avoid LV pacing at scarred areas also appears promising. ${ }^{(69,70)}$ Trials evaluating AV and ventricularventricular (VV) optimisation after CRT implantation have largely yielded negative results. Compared to default settings, neither echocardiographic nor algorithm-based $\mathrm{AV}$ and $\mathrm{V} \mathrm{V}$ optimisation confers long-term benefits. ${ }^{(71,72,73)}$

\section{CONCLUSION}

Despite the evidence supporting ICD and CRT use in heart failure management, the implantation rate remains low in Singapore and the rest of Southeast Asia, even in patients who fulfil the clinical indications as stipulated in current guidelines. ${ }^{(74)}$ Among Asian patients, data on device efficacy appears inconsistent. ${ }^{(75,76)}$ More research is therefore necessary to evaluate device efficacy in Asian heart failure patients and study the cost-effectiveness of such device therapy in the healthcare systems of the various Asian countries. Finally, it is important to raise awareness of the clinical benefits of ICD and CRT in heart failure treatment among healthcare professionals managing cardiac failure patients, so that they can initiate appropriate referrals for device implantation.

\section{REFERENCES}

1. Singapore Myocardial Infarction Registry; National Registry of Diseases Office; Ministry of Health Singapore. Available at: https://www.nrdo.gov.sg/ docs/librariesprovider3/Publications---AMI/sinmyocardinfreg2007-2012. pdf?sfvrsn=0. Accessed October 5, 2015.

2. Solomon SD, Wang D, Finn P, et al. Effect of candesartan on causespecific mortality in heart failure patients: the Candesartan in Heart failure Assessment of Reduction in Mortality and morbidity (CHARM) program. Circulation 2004; 110:2180-3.

3. Cleland JG, Massie BM, Packer M. Sudden death in heart failure: vascular or electrical? Eur J Heart Fail 1999; 1:41-5.

4. Gradman A, Deedwania P, Cody R, et al. Predictors of total mortality and sudden death in mild to moderate heart failure. Captopril-Digoxin Study Group. J Am Coll Cardiol 1989; 14:564-70.
5. Szabó BM, van Veldhuisen DJ, Crijns HJ, et al. Value of ambulatory electrocardiographic monitoring to identify increased risk of sudden death in patients with left ventricular dysfunction and heart failure. Eur Heart J 1994; 15:928-33.

6. Doval HC, Nul DR, Grancelli HO, et al. Nonsustained ventricular tachycardia in severe heart failure. Independent marker of increased mortality due to sudden death. GESICA- GEMA Investigators. Circulation 1996; 94:3198-203.

7. The Antiarrhythmics versus Implantable Defibrillators (AVID) Investigators. A comparison of antiarrhythmic-drug therapy with implantable defibrillators in patients resuscitated from near-fatal ventricular arrhythmias. $\mathrm{N} \mathrm{Engl} \mathrm{J}$ Med 1997; 337:1576-83.

8. Wever EF, Hauer RN, van Capelle FL, et al. Randomised study of implantable defibrillator as first-choice therapy versus conventional strategy in postinfarct sudden death survivors. Circulation 1995; 91:2195-203.

9. Siebels J, Kuck KH. Implantable cardioverter defibrillator compared with antiarrhythmic drug treatment in cardiac arrest survivors (the Cardiac Arrest Study Hamburg). Am Heart J 1994; 127(4 Pt 2):1139-44.

10. Connolly SJ, Gent M, Roberts RS, et al. Canadian implantable defibrillator study (CIDS): a randomized trial of the implantable cardioverter defibrillator against amiodarone. Circulation 2000; 101:1297-302.

11. Kuck KH, Cappato R, Siebels J, Ruppel R. Randomized comparison of antiarrhythmic drug therapy with implantable defibrillators in patients resuscitated from cardiac arrest: the Cardiac Arrest Study Hamburg (CASH). Circulation 2000; 102:748-54.

12. Connolly SJ, Hallstrom AP, Cappato R, et al. Meta-analysis of the implantable cardioverter defibrillator secondary prevention trials. AVID, CASH and CIDS studies. Antiarrhythmics vs Implantable Defibrillator study. Cardiac Arrest Study Hamburg. Canadian Implantable Defibrillator Study. Eur Heart J 2000; 21:2071-8.

13. Bardy GH, Lee KL, Mark DB, et al; Sudden Cardiac Death in Heart Failure Trial (SCD-HeFT) Investigators. Amiodarone or an implantable cardioverter-defibrillator for congestive heart failure. N Engl J Med 2005; 352:225-37.

14. Packer DL, Prutkin JM, Hellkamp AS, et al. Impact of implantable cardioverter-defibrillator, amiodarone, and placebo on the mode of death in stable patients with heart failure: analysis from the sudden cardiac death in heart failure trial. Circulation 2009; 120:2170-6.

15. Moss AJ, Zareba W, Hall WJ, et al; Multicenter Automatic Defibrillator Implantation Trial II Investigators. Prophylactic implantation of a defibrillator in patients with myocardial infarction and reduced ejection fraction. N Engl J Med 2002; 346:877-83.

16. Goldenberg I, Moss AJ, McNitt S, et al; MADIT-II Investigators. Time dependence of defibrillator benefit after coronary revascularisation in the Multicenter Automatic Defibrillator Implantation Trial (MADIT)-II. J Am Coll Cardiol 2006; 47:1811-7.

17. Kadish A, Dyer A, Daubert JP, et al; Defibrillators in Non-Ischemic Cardiomyopathy Treatment Evaluation (DEFINITE) Investigators. Prophylactic defibrillator implantation in patients with nonischemic dilated cardiomyopathy. N Engl J Med 2004; 350:2151-8.

18. Desai AS, Fang JC, Maisel WH, Baughman KL. Implantable defibrillators for the prevention of mortality in patients with nonischemic cardiomyopathy: a meta-analysis of randomized controlled trials. JAMA 2004; 292:2874-9.

19. Priori SG, Blomström-Lundqvist C, Mazzanti A, et al; Authors/Task Force Members; Document Reviewers. 2015 ESC Guidelines for the management of patients with ventricular arrhythmias and the prevention of sudden cardiac death: The Task Force for the Management of Patients with Ventricular Arrhythmias and the Prevention of Sudden Cardiac Death of the European Society of Cardiology (ESC) Endorsed by: Association for European Paediatric and Congenital Cardiology (AEPC). Eur Heart J 2015: 36:2793-867.

20. Epstein AE, Kay GN, Plumb VJ, et al; ACT Investigators. Implantable cardioverter-defibrillator prescription in the elderly. Heart Rhythm 2009; 6:1136-43.

21. Healey JS, Hallstrom AP, Kuck KH, et al. Role of the implantable defibrillator among elderly patients with a history of life-threatening ventricular arrhythmias. Eur Heart J 2007; 28:1746-9.

22. Santangeli P, Di Biase L, Dello Russo A, et al. Meta-analysis: age and effectiveness of prophylactic implantable cardioverter-defibrillators. Ann Intern Med 2010; 153:592-9.

23. Setoguchi S, Nohria A, Rassen JA, Stevenson LW, Schneeweiss S. Maximum potential benefit of implantable defibrillators in preventing sudden death after hospital admission because of heart failure. CMAJ 2009; 180:611-6.

24. Dewland TA, Pellegrini CN, Wang Y, et al. Dual-chamber implantable cardioverter-defibrillator selection is associated with increased 
complication rates and mortality among patients enrolled in the NCDR implantable cardioverter-defibrillator registry. J Am Coll Cardiol 2011 58:1007-13.

25. Dorian P, Philippon F, Thibault B, et al. Randomized controlled study of detection enhancements versus rate-only detection to prevent inappropriate therapy in a dual-chamber implantable cardioverter-defibrillator. Heart Rhythm 2004; 1:540-7.

26. Bänsch D, Steffgen F, Grönefeld G, et al. The 1+1 trial: a prospective tria of a dual- versus a single-chamber implantable defibrillator in patients with slow ventricular tachycardias. Circulation 2004; 110:1022-9.

27. Friedman PA, McClelland RL, Bamlet WR, et al. Dual-chamber versus single-chamber detection enhancements for implantable defibrillator rhythm diagnosis: the detect supraventricular tachycardia study. Circulation 2006; 113:2871-9.

28. Swerdlow CD, Chen PS, Kass RM, Allard JR, Peter CT. Discrimination of ventricular tachycardia from sinus tachycardia and atrial fibrillation in a tiered-therapy cardioverter-defibrillator. J Am Coll Cardiol 1994; 23:1342-55.

29. Rinaldi CA, Simon RD, Baszko A, et al. A 17 year experience of inappropriate shock therapy in patients with implantable cardioverterdefibrillators: are we getting any better? Heart 2004; 90:330-1.

30. Epstein AE, DiMarco JP, Ellenbogen KA, et al; American College of Cardiology/American Heart Association Task Force on Practice Guidelines (Writing Committee to Revise the ACC/AHA/NASPE 2002 Guideline Update for Implantation of Cardiac Pacemakers and Antiarrhythmia Devices); American Association for Thoracic Surgery; Society of Thoracic Surgeons. ACC/AHA/HRS 2008 Guidelines for Device-Based Therapy of Cardiac Rhythm Abnormalities: a report of the American College of Cardiology/American Heart Association Task Force on Practice Guidelines (Writing Committee to Revise the ACC/AHA/NASPE 2002 Guideline Update for Implantation of Cardiac Pacemakers and Antiarrhythmia Devices) developed in collaboration with the American Association fo Thoracic Surgery and Society of Thoracic Surgeons. J Am Coll Cardio 2008; 51:e1-62.

31. Young JB, Abraham WT, Smith AL, et al; Multicenter InSync ICD Randomized Clinical Evaluation (MIRACLE ICD) Trial Investigators Combined cardiac resynchronisation and implantable cardioversion defibrillation in advanced chronic heart failure: the MIRACLE ICD Trial. JAMA 2003; 289:2685-94.

32. Bristow MR, Saxon LA, Boehmer J, et al; Comparison of Medical Therapy, Pacing, and Defibrillation in Heart Failure (COMPANION) Investigators. Cardiac-resynchronization therapy with or without an implantable defibrillator in advanced chronic heart failure. N Engl J Med 2004 350:2140-50

33. Cleland JG, Daubert JC, Erdmann E, et al; Cardiac ResynchronizationHeart Failure (CARE-HF) Study Investigators. The effect of cardiac resynchronization on morbidity and mortality in heart failure. $\mathrm{N}$ Engl J Med 2005; 352:1539-49.

34. Bilchick KC, Kamath S, DiMarco JP, Stukenborg GJ. Bundle-branch block morphology and other predictors of outcome after cardiac resynchronization therapy in Medicare patients. Circulation 2010; 122:2022-30.

35. Gold MR, Thébault C, Linde C, et al. Effect of QRS duration and morphology on cardiac resynchronization therapy outcomes in mild heart failure: results from the Resynchronization Reverses Remodeling in Systolic Left Ventricular Dysfunction (REVERSE) study. Circulation 2012; 126:822-9.

36. Cunnington C, Kwok CS, Satchithananda DK, et al. Cardiac resynchronisation therapy is not associated with a reduction in mortality or heart failure hospitalisation in patients with non-left bundle branch block QRS morphology: meta-analysis of randomised controlled trials. Heart 2015; 101:1456-62.

37. Sipahi I, Chou JC, Hyden M, et al. Effect of QRS morphology on clinical event reduction with cardiac resynchronization therapy: meta-analysis of randomized controlled trials. Am Heart J 2012; 163:260-7.e3.

38. Moss AJ, Hall WJ, Cannom DS, et al; MADIT-CRT Trial Investigators. Cardiac-resynchronization therapy for the prevention of heart-failure events. N Engl J Med 2009; 361:1329-38.

39. Tang AS, Wells GA, Talajic M, et al; Resynchronization-Defibrillation for Ambulatory Heart Failure Trial Investigators. Cardiac-resynchronization therapy for mild-to-moderate heart failure. N Engl J Med 2010; 363:2385-95

40. Wilkoff BL, Cook JR, Epstein AE, et al; Dual Chamber and VVI Implantable Defibrillator Trial Investigators. Dual-chamber pacing or ventricular back-up pacing in patients with an implantable defibrillator: the Dual Chamber and VVI Implantable Defibrillator (DAVID) Trial. JAMA 2002; 288:3115-23.

41. Sweeney MO, Hellkamp AS, Ellenbogen KA, et al; MOde Selection Trial Investigators. Adverse effect of ventricular pacing on heart failure and atrial fibrillation among patients with normal baseline QRS duration in a clinical trial of pacemaker therapy for sinus node dysfunction. Circulation 2003; 107:2932-7.

42. Leclercq C, Cazeau S, Lellouche D, et al. Upgrading from single chamber right ventricular to biventricular pacing in permanently paced patients with worsening heart failure: The RD-CHF study. Pacing Clin Electrophysiol 2007; 30 Suppl 1:S23-30.

43. Curtis AB, Worley SJ, Adamson PB, et al; Biventricular versus Right Ventricular Pacing in Heart Failure Patients with Atrioventricular Block (BLOCK HF) Trial Investigators. Biventricular pacing for atrioventricular block and systolic dysfunction. N Engl J Med 2013; 368:1585-93.

44. Wilton SB, Leung AA, Ghali WA, Faris P, Exner DV. Outcomes of cardiac resynchronization therapy in patients with versus those without atrial fibrillation: a systematic review and meta-analysis. Heart Rhythm 2011; 8:1088-94.

45. Upadhyay GA, Choudhry NK, Auricchio A, Ruskin J, Singh JP. Cardiac resynchronization in patients with atrial fibrillation: a meta-analysis of prospective cohort studies. J Am Coll Cardiol 2008; 52:1239-46.

46. Gasparini $M$, Leclercq $C$, Lunati $M$, et al. Cardiac resynchronization therapy in patients with atrial fibrillation: the CERTIFY study (Cardiac Resynchronization Therapy in Atrial Fibrillation Patients Multinational Registry). JACC Heart Fail 2013; 1:500-7.

47. Penn J, Goldenberg I, Moss AJ, et al; MADIT-CRT Trial Investigators. Improved outcome with preventive cardiac resynchronization therapy in the elderly: a MADIT-CRT substudy. J Cardiovasc Electrophysiol 2011; 22:892-97.

48. Killu AM, Wu JH, Friedman PA, et al. Outcomes of cardiac resynchronization therapy in the elderly. Pacing Clin Electrophysiol 2013; 36:664-72.

49. Höke $U$, Putter $H$, Van Der Velde ET, et al. Left ventricular reverse remodeling, device-related adverse events, and long-term outcome after cardiac resynchronization therapy in the elderly. Circ Cardiovasc Qual Outcomes 2014; 7:437-44.

50. Olechowski B, Sands R, Zachariah D, et al. Is cardiac resynchronisation therapy feasible, safe and beneficial in the very elderly? J Geriatr Cardiol $2015 ; 12: 497-501$

51. Dickstein K, Vardas PE, Auricchio A, et al; Committee for Practice Guidelines of the European Society of Cardiology; ESC Committee for Practice Guidelines (CPG). 2010 focused update of ESC Guidelines on device therapy in heart failure: an update of the 2008 ESC Guidelines for the diagnosis and treatment of acute and chronic heart failure and the 2007 ESC Guidelines for cardiac and resynchronization therapy. Developed with the special contribution of the Heart Failure Association and the European Heart Rhythm Association. Eur J Heart Fail 2010; 12:1143-53.

52. Yancy CW, Jessup M, Bozkurt B, et al; American College of Cardiology Foundation; American Heart Association Task Force on Practice Guidelines. 2013 ACCF/AHA guideline for the management of heart failure: a report of the American College of Cardiology Foundation/American Heart Association Task Force on Practice Guidelines. J Am Coll Cardiol 2013; 62:e147-239.

53. Thibault B, Harel F, Ducharme A, et al; LESSER-EARTH Investigators. Cardiac resynchronization therapy in patients with heart failure and a QRS complex <120 milliseconds: the Evaluation of Resynchronization Therapy for Heart Failure (LESSER-EARTH) trial. Circulation 2013; 127:873-81.

54. Ruschitzka F, Abraham WT, Singh JP, et al; EchoCRT Study Group. Cardiacresynchronization therapy in heart failure with a narrow QRS complex. N Engl J Med 2013; 369:1395-405

55. Versteeg H, Schiffer AA, Widdershoven JW, et al. Response to cardiac resynchronization therapy: is it time to expand the criteria? Pacing Clin Electrophysiol 2009; 32:1247-56.

56. Packer M. Proposal for a new clinical end point to evaluate the efficacy of drugs and devices in the treatment of chronic heart failure. J Card Fail 2001; 7:176-82.

57. Pitzalis MV, lacoviello $M$, Romito $R$, et al. Cardiac resynchronization therapy tailored by echocardiographic evaluation of ventricular asynchrony. J Am Coll Cardiol 2002; 40:1615-22.

58. $\mathrm{Yu}$ CM, Fung $\mathrm{WH}$, Lin $\mathrm{H}$, et al. Predictors of left ventricular reverse remodeling after cardiac resynchronization therapy for heart failure secondary to idiopathic dilated or ischemic cardiomyopathy. Am J Cardiol 2003; 91:684-8.

59. Bleeker GB, Bax JJ, Fung JW, et al. Clinical versus echocardiographic parameters to assess response to cardiac resynchronization therapy. Am J Cardiol 2006; 97:260-3.

60. Adelstein EC, Saba S. Scar burden by myocardial perfusion imaging predicts echocardiographic response to cardiac resynchronization therapy in ischemic cardiomyopathy. Am Heart J 2007; 153:105-12. 
61. Chalil S, Foley PW, Muyhaldeen SA, et al. Late gadolinium enhancementcardiovascular magnetic resonance as a predictor of response to cardiac resynchronization therapy in patients with ischaemic cardiomyopathy. Europace 2007; 9:1031-7.

62. Leyva F, Taylor RJ, Foley PW, et al. Left ventricular midwall fibrosis as a predictor of mortality and morbidity after cardiac resynchronization therapy in patients with nonischemic cardiomyopathy. J Am Coll Cardiol 2012; 60:1659-67.

63. Chalil S, Stegemann B, Muhyaldeen S, et al. Intraventricular dyssynchrony predicts mortality and morbidity following cardiac resynchronization therapy: a study using cardiovascular magnetic resonance tissue synchronization imaging. J Am Coll Cardiol 2007; 50:243-52.

64. Arshad A, Moss AJ, Foster E, et al; MADIT-CRT Executive Committee. Cardiac resynchronization therapy is more effective in women than in men: the MADIT-CRT (Multicenter Automatic Defibrillator Implantation Trial with Cardiac Resynchronization Therapy) trial. J Am Coll Cardiol 2011; 57:813-20.

65. Leyva F, Foley PW, Chalil S, Irwin N, Smith RE. Female gender is associated with a better outcome after cardiac resynchronization therapy. Pacing Clin Electrophysiol 2011; 34:82-8.

66. Chung ES, Leon AR, Tavazzi L, et al. Results of the Predictors of Response to CRT (PROSPECT) Trial. Circulation 2008; 117:2608-16.

67. Khan FZ, Virdee MS, Palmer CR, et al. Targeted left ventricular lead placement to guide cardiac resynchronization therapy: the TARGET study: a randomized, controlled trial. J Am Coll Cardiol 2012; 59:1509-18.

68. Saba S, Marek J, Schwartzman D, et al. Echocardiography-guided left ventricular lead placement for cardiac resynchronization therapy: results of the Speckle Tracking Assisted Resynchronization Therapy for Electrode Region trial. Circ Heart Fail 2013; 6:427-34.
69. Leyva F, Foley PW, Chalil S, et al. Cardiac resynchronization therapy guided by late gadolinium-enhancement cardiovascular magnetic resonance. J Cardiovasc Magn Reson 2011; 13:29-38.

70. White JA, Yee R, Yuan X, et al. Delayed enhancement magnetic resonance imaging predicts response to cardiac resynchronization therapy in patients with intraventricular dyssynchrony. J Am Coll Cardiol 2006; 48:1953-60.

71. Ellenbogen KA, Gold MR, Meyer TE, et al. Primary results from the SmartDelay determined AV optimization: a comparison to other AV delay methods used in cardiac resynchronization therapy (SMART-AV) trial: a randomized trial comparing empirical, echocardiographyguided, and algorithmic atrioventricular delay programming in cardiac resynchronization therapy. Circulation 2010; 122:2660-8.

72. Abraham WT, Gras D, Yu CM, Guzzo L, Gupta MS; FREEDOM Steering Committee. Rationale and design of a randomized clinical trial to assess the safety and efficacy of frequent optimization of cardiac resynchronization therapy: the Frequent Optimization Study Using the QuickOpt Method (FREEDOM) trial. Am Heart J 2010; 159:944-948.e1.

73. Martin DO, Lemke B, Birnie D, et al; Adaptive CRT Study Investigators. Investigation of a novel algorithm for synchronized left-ventricular pacing and ambulatory optimization of cardiac resynchronization therapy: results of the adaptive CRT trial. Heart Rhythm 2012; 9:1807-14.

74. Lee E, Chen R, Aziz S, et al. Socio cultural barriers to device therapy among Asian patients with heart failure. Eur J Heart Fail 2012; 11 (Suppl 1):S268.

75. Tanno K, Miyoshi F, Watanabe N, et al; MADIT II. The Multicenter Automtic Defibrillator Implantation Trial. Are the MADIT II criteria for ICD implantation appropriate for Japanese patients? Circ J 2005; 69:19-22.

76. Siu CW, Pong V, Ho HH, et al. Are MADIT II criteria for implantable cardioverter defibrillator implantation appropriate for Chinese patients? J Cardiovasc Electrophysiol 2010; 21:231-5. 